\title{
Correction to: Shear wave elastography assessment and comparison study of the Achilles tendons in optimally conditioned asymptomatic young collegiate athletes
}

Felix M. Gonzalez ${ }^{1,2} \mathbb{D} \cdot$ Courtney N. Gleason ${ }^{3} \cdot$ Kenneth S. Lee $^{4} \cdot$ Sameh A. Labib $^{3} \cdot$ Levon N. Nazarian $^{5}$. William B. Morrison ${ }^{5}$. David A. Reiter ${ }^{1,3}$

Published online: 20 May 2021

(c) ISS 2021

\section{Correction to: Skeletal Radiology}

https://doi.org/10.1007/s00256-021-03798-5

The name of Courtney N. Gleason was incorrectly captured in the original manuscript and is corrected in this article.

Publisher's note Springer Nature remains neutral with regard to jurisdictional claims in published maps and institutional affiliations.

The original article can be found online at https://doi.org/10.1007/ s00256-021-03798-5.

Felix M. Gonzalez

felix.m.gonzalez@emory.edu

1 Department of Radiology and Imaging Sciences, Emory School of Medicine, 59 Executive Park South, 4th Floor Suite 4009, Atlanta, GA 30329, USA

2 Department of Radiology and Imaging Sciences, Section of Musculoskeletal Imaging, Emory University Hospital, 59 Executive Park South, 4th Floor Suite 4009, Atlanta, GA 30329, USA

3 Department of Orthopaedic Surgery, Emory School of Medicine, Atlanta, Ga, USA

4 Department of Radiology, University of Wisconsin, Madison, WI, USA

5 Department of Radiology, Thomas Jefferson University and Hospitals, Philadelphia, PA, USA 